\title{
Coupons for health care a sign of creeping privatization?
}

- Cite as: CMAJ 2019 December 9;191:E1364. doi: 10.1503/cmaj.1095822

Posted on cmajnews.com on November 18, 2019

T he online discount site Groupon, home to cut-price gym memberships and spa visits, may seem like a strange place to find deals on medical procedures, but some Toronto-area clinics are offering just that.

One medical imaging clinic in Vaughn, Accurate Imaging Diagnostics, recently offered a hefty discount on a full body scan used to measure bone loss and track progress on bodybuilding and weight-loss regimens. People who buy the Dual Energy X-ray Absorptiometry or DEXA scan via Groupon pay $\$ 79$ instead of the usual $\$ 125$. The promotion aims to drum up interest in the service, which is not covered by provincial health insurance.

"DEXA is quite a new service, so not a lot of people know what it is or why to get it," says Maryna Tokar, marketing manager for Accurate Imaging Diagnostics. The clinic has sold around 300 coupons in 18 months and sees about 20 new patients every month who have purchased a coupon from Groupon. A referral from a doctor, nurse practitioner, dentist, chiropodist or chiropractor is required to undergo the scan, but the clinic also has an in-house physician.

Studio Athletica Sports Medicine clinic in Toronto offers a similar deal. And in the United States, Groupon deals for CT scans, ultrasounds and various other imaging services abound. There are also coupons for services that allow patients to save money by bundling hospital fees together if they pay upfront.

Some Canadian health care experts are troubled by these promotions running alongside the provision of publicly funded services. "It's an example of the creeping privatization lurking around our healthcare system," says Dr. Jacalyn Duffin, a haematologist and medical historian at Queen's University.

Private imaging clinics seem to be on the rise in Canada, Duffin notes, but it's unclear how they are allowed under the Canada Health Act. She worries that private clinics will drive up costs without reducing waitlists. "Gradually with these private services, the public system offers less and less," Duffin says.

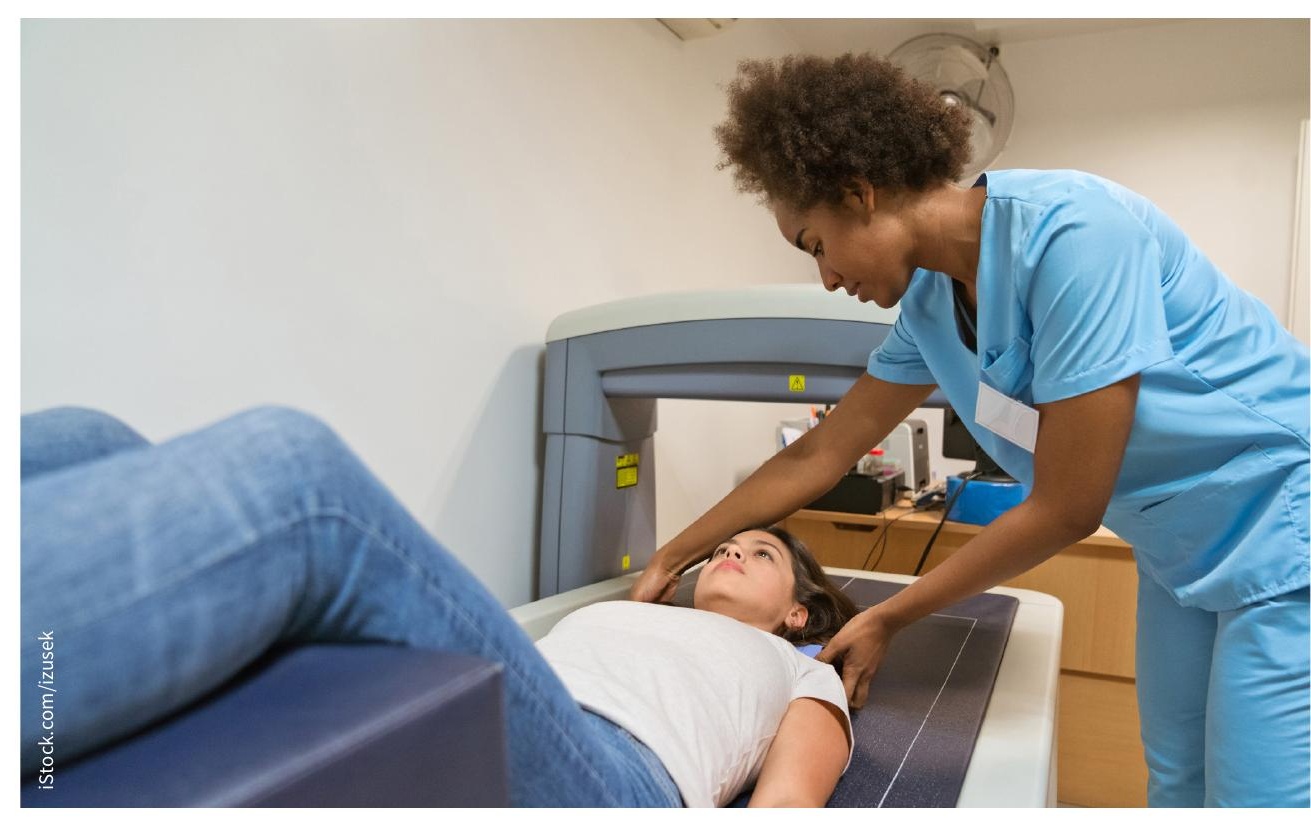

Some private clinics are offering US-style Groupon deals to the dismay of advocates for Canada's public health care system.

Melanie Benard, director of policy and advocacy at the Canadian Health Coalition, says the marketing of medical imaging on Groupon is disturbing. "Although it may not overtly violate the Canada Health Act, it certainly does seem to skirt around it and violate the spirit of the law," she says. "The Groupon phenomenon is a level of marketization that is taking it to a whole other level in terms of making it a profit-seeking industry rather than focusing on patients' wellbeing," she adds.

Benard is concerned about the potential health risks to patients who undergo unnecessary scans, which may "increase their exposure to radiation and could be potentially harmful in the long run," she says. According to Tokar, the radiation from a DEXA scan is very low and lower than a standard X-ray. 